\title{
The Concurrence of Hypercholesterolemia and Aging Promotes DNA Damage in Apolipoprotein E-Deficient Mice
}

\author{
Sara P. Dalboni ${ }^{1}$, Bianca P. Campagnaro ${ }^{2}$, Clarissa L. Tonini ${ }^{2}$, Elisardo C. Vasquez, \\ Silvana S. Meyrelles ${ }^{1,2^{*}}$
}

${ }^{1}$ Biotechnology Graduate Program, Health Sciences Center, Federal University of Espirito Santo, Vitoria, Brazil; ${ }^{2}$ Department of Physiological Sciences, Health Sciences Center, Federal University of Espirito Santo, Vitoria, Brazil; ${ }^{3}$ Emescam College of Health Sciences, Vitoria, Brazil.

Email: *smeyrelles@pq.cnpq.br

Received July 26 $6^{\text {th }}, 2012$; revised August $27^{\text {th }}, 2012$; accepted September $5^{\text {th }}, 2012$

\begin{abstract}
Recent evidence shows that increased oxidative stress and aging contribute to DNA damage in various cardiovascular diseases such as lipid disorders and atherosclerosis. In the present study, we used the comet assay to evaluate the influence of aging on DNA damage in whole blood cells from apolipoprotein E-deficient (apoE ${ }^{-/}$) mice and compared the results to those found in cells from wild-type C57BL/6 (C57) mice. Using the alkaline comet assay and fluorescent ethidium bromide staining, DNA damage was analyzed in the peripheral whole blood $(5 \mu \mathrm{L})$ cells that were isolated from either young (8-week-old) and elderly (72-week-old) apoE ${ }^{-/}$mice or from age-matched C57 mice. The levels of total plasma cholesterol were approximately 6-fold higher in $\mathrm{apoE}^{-/-}$mice of both ages compared to $\mathrm{C} 57$ mice. Elderly apoE $\mathrm{E}^{-/-}$mice showed significantly higher levels of DNA damage $(19 \%)$ compared to elderly C57 mice $(8 \%, \mathrm{p}<0.01)$ and young apoE $\mathrm{E}^{-/-}$mice $(10 \%, \mathrm{p}<0.01)$. The comet assay in whole blood cells is a suitable technique for the detection of DNA damage in the apoE ${ }^{---}$mouse; it is an easy, rapid, inexpensive and sensitive method. The novelty of this study is that DNA damage occurring in whole blood cells of this murine model requires the concurrence of aging and oxidative stress-related hypercholesterolemia.
\end{abstract}

Keywords: DNA Damage; Oxidative Stress; ApoE Knockout Mice; Aging; Blood Cells

\section{Introduction}

The current evidence supports a crucial role for oxidative stress in atherosclerosis, a progressive disease that results from lipid disorders and affects both large- and mediumsize vessels [1]. The apolipoprotein E-deficient $\left(\mathrm{apoE}^{-/}\right)$ mouse, which spontaneously develops hypercholesterolemia and atherosclerotic lesions [2], has provided a significant contribution to understanding the role of oxidative stress in atherosclerosis.

The phenotypes of the apoE ${ }^{-/-}$mouse include age-dependent vascular senescence [3], an increase in vascular oxidative stress [4], and an imbalance in the production of cardiac and vascular nitric oxide (NO) and reactive oxygen species (ROS) [2]. Because DNA is a cellular target of ROS [5] and atherosclerotic disease is aggravated by aging $[3,6]$, we investigated aging-related DNA damage using this murine model.

The comet assay, a quantitative measure of DNA genotoxicity in the cells of any tissue [7,8], has been used to analyze DNA damage. With this method, Folk-

${ }^{*}$ Corresponding author. mann et al. [9] showed that old apoE $\mathrm{E}^{-/-}$mice suffer from hepatic oxidative stress due to oxidized DNA. However, the influence of aging on DNA damage in whole blood cells, which are advantageous to use because they are not damaged during isolation [9], has not yet been investigated using this experimental model of atherosclerosis.

Therefore, the aim of the present study was to test the hypothesis that atherosclerosis and aging lead to DNA damage in the blood cells of elderly hypercholesterolemic animals but not in those of young animals when both are compared to age-matched normocholesterolemic mice.

\section{Material and Methods}

\subsection{Animals}

Experiments were performed in male and female wildtype C57BL/6 (C57) and apolipoprotein E-deficient $\left(\mathrm{apoE}^{-/}\right)$mice bred and maintained in the animal care facility at the Laboratory of Transgenes in the Health Sciences Center at the Federal University of Espirito Santo, Brazil. The mice were housed in individual plastic 
cages with a controlled temperature $\left(22^{\circ} \mathrm{C}-23^{\circ} \mathrm{C}\right)$ and humidity $(60 \%)$ and were exposed to a $12: 12$-h light-dark cycle. All mice were fed a standard chow diet and had access to water ad libitum. The mice were distributed into 2 groups of young (8-week-old) $\operatorname{apoE}^{-/}(\mathrm{n}=8)$ and $\mathrm{C} 57(\mathrm{n}=8)$ mice and 2 groups of elderly (72-week-old) $\operatorname{apoE}^{-/-}(\mathrm{n}=8)$ and $\mathrm{C} 57(\mathrm{n}=8)$ mice. All experimental procedures were performed in accordance with the guidelines for the care and handling of laboratory animals as recommended by the National Institutes of Health (NIH), and study protocols were previously approved by the Institutional Animal Care Committee (CEUA-Emescam, Protocol \# 014/2011).

\subsection{Blood Samples}

Animals were euthanized at the desired age through an anesthetic overdose (sodium thiopental, $100 \mathrm{mg} / \mathrm{kg}$, i.p.). The chest was opened and the blood was collected from the left atrium and stored in a freezer at $-80^{\circ} \mathrm{C}$ until further analysis.

\subsection{Comet Assay}

The DNA damage in peripheral whole blood cells was analyzed using the alkaline $(\mathrm{pH}>13)$ comet assay according to Singh et al. [10] with minor modifications and under low brightness due to the photo sensitivity of the assay.

The histological slides were precoated with $200 \mu \mathrm{L}$ of $1.5 \%$ normal melting point agarose (in distilled water) in a water-bath at $60^{\circ} \mathrm{C}$. Subsequently, $5 \mu \mathrm{L}$ of peripheral blood was mixed with $100 \mu \mathrm{L}$ of $1 \%$ low melting point agarose in PBS at $37^{\circ} \mathrm{C}$ and spread on agarose-precoated slides using cover slips. After gelling at $4^{\circ} \mathrm{C}$ for $20 \mathrm{~min}$, the cover slips were removed and the slides were immersed in freshly prepared, cold lysis solution $(2.5 \mathrm{M}$ $\mathrm{NaCl}, 100 \mathrm{mM}$ EDTA, 10 mMTris, adjusted to $\mathrm{pH} 10$ 10.5 using freshly added $1 \%$ Triton X-100 and 10\% DMSO) for 1 hour at $4^{\circ} \mathrm{C}$. After washing for $5 \mathrm{~min}$ in cold distilled water, the slides were placed in an electrophoresis chamber containing freshly prepared alkaline buffer $(300 \mathrm{mMNaOH}, 1 \mathrm{mM}$ EDTA, $\mathrm{pH}>13)$ for 20 min at $4^{\circ} \mathrm{C}$, and electrophoresis was then performed at $300 \mathrm{~mA}$ and $25 \mathrm{~V}$ for $30 \mathrm{~min}$. Afterwards, the slides were neutralized with a $0.4 \mathrm{M}$ Tris buffer $(\mathrm{pH}=7.5)$, for $5 \mathrm{~min}$, washed with cold distilled water and allowed to dry at room temperature for 1 hour.

Samples were then stained with $50 \mu \mathrm{L}$ of ethidium bromide $(20 \mu \mathrm{g} / \mathrm{mL}$, Sigma-Aldrich) and covered with coverslips. Immediately afterwards, images were obtained at a magnification of $\times 20$ using an inverted fluorescence optical microscope (Olympus BX60) equipped with excitation $(510-550 \mathrm{~nm})$ and barrier $(590 \mathrm{~nm})$ filters. The coded images were acquired before scoring using a CCD camera (Nikon, Japan) and were analyzed using the CASP program (public domain). The tail moment and the percentage of DNA in the tail were chosen from among the options offered by the CASP program and were used to quantify DNA fragmentation. DNA damage was quantified and categorized into five levels of genotoxicity according to the comet tail size: 0 (intact comets), 1 (1\% - 25\% damage), 2 (25\% - 45\% damage), 3 (45\% - 70\% damage) and 4 (more than 70\% damage). All of the samples were coded before scoring. The extent of DNA damage was expressed in arbitrary units (AU) and calculated using the following formula:

$$
\text { A.U. }=\frac{\begin{array}{l}
0(n \text { level } 0)+1(n \text { level } 1)+2(n \text { level } 2) \\
+3(n \text { level } 3)+4(n \text { level } 4) \times 100
\end{array}}{\text { total comets analyzed }}
$$

The images of 100 randomly selected cells from each sample, 50 cells from each of two replicate slides, were analyzed by two individuals for each animal. This process generated two values of AU for DNA damage, and the final result for each animal was the average of these values.

\subsection{Statistical Analysis}

All data are expressed as the mean \pm SEM. The normality (Gaussian distribution) of the variables was previously analyzed using the Kolmogorov-Smirnov test, and each of the four groups was significant. The statistical analyses for DNA damage and the level of genotoxicity were performed using the two-way analysis of variance (ANOVA). When the ANOVA showed significant differences, the Bonferroni's test was performed as a post$h o c$ analysis. The differences were considered significant when $\mathrm{p}<0.05$.

\section{Results}

The body weights of the two youngest strains of mice were not different, but there was a significant age-dependent weight gain in C57 (from $22.6 \pm 0.3$ to $31.9 \pm 1.2 \mathrm{~g}$ ) and apoE $^{-/}$(from $22.1 \pm 1.1$ to $32.8 \pm 1.1 \mathrm{~g}$ ) mice. The daily chow and water intakes were similar between the two age-matched strains of mice. As expected, the total plasma cholesterol levels were significantly higher in the young and aged apoE ${ }^{-/-}$mice (6.3-fold and 6-fold, respecttively) than in the age-matched C57 mice ( $86 \pm 9.5$ and $97 \pm 8.8 \mathrm{mg} / \mathrm{dL}$, respectively, $\mathrm{p}<0.01)$. The two strains of mice had no significant age-related differences (Figure 1, bottom panel).

We excluded comets without clearly identifiable heads or comets with most of their DNA in their tails after electrophoresis during the image analysis. Figure 1 (top panel) shows the average percent of DNA in the tail in both strains of mice, which reflects the break frequency. 

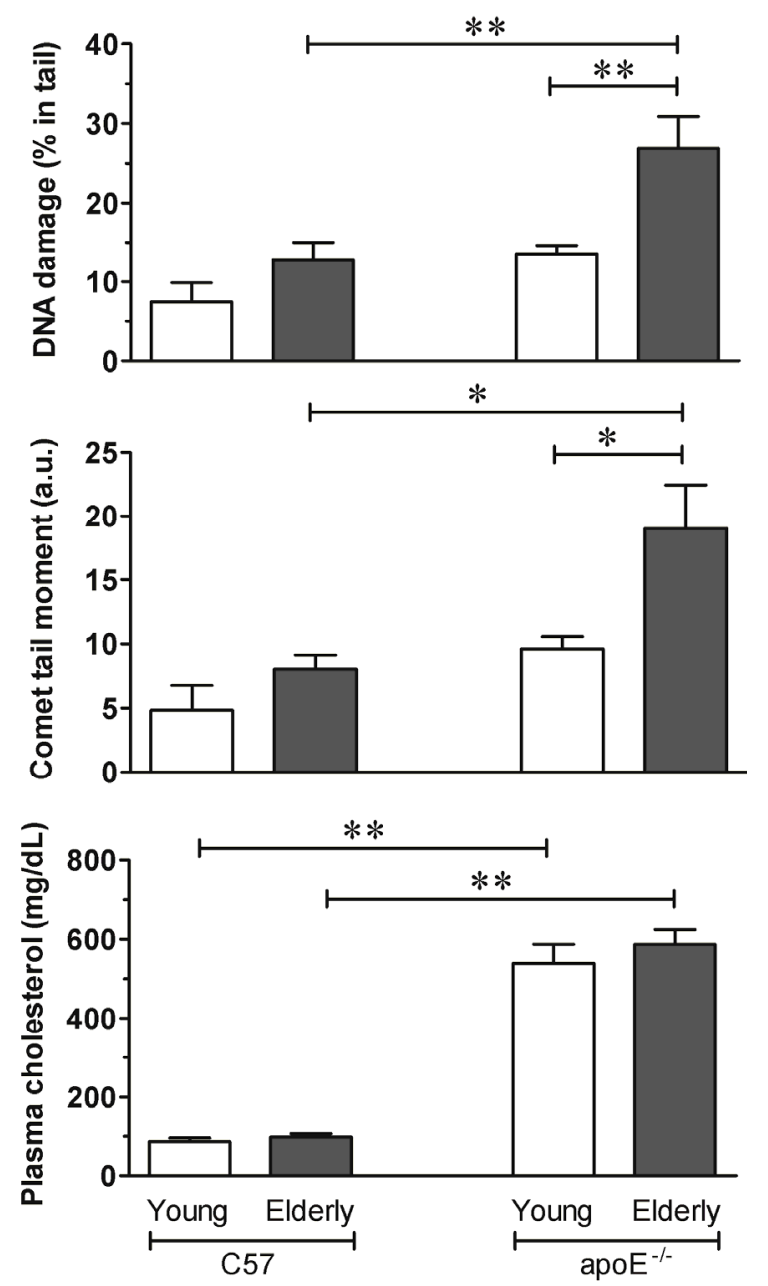

Figure 1. The comet assay and total plasma cholesterol. The bar graphs show DNA damage in the blood cells from elderly but not young hypercholesterolemic apoE ${ }^{-/-}$mice compared to age-matched wild-type C57 mice. The values are shown as the means \pm SEM (7 animals per group). $p<0.05$ and ${ }^{* *} p$ $<0.01$ (two-way ANOVA).

Both the young and elderly C57 mice showed a similar percentage of DNA in the tail: $7.4 \% \pm 2.4 \%$ and $13 \% \pm$ $2.1 \%$, respectively. The young apoE ${ }^{-/-}$mice did not show a statistically significant increase in levels of DNA in the tail $(14 \% \pm 1.0 \%)$ despite their high levels of total plasma cholesterol. In contrast, the elderly animals of this strain had similar levels of plasma cholesterol and showed a significant increase in levels of DNA in the tail $(27 \% \pm 4.0 \%, \mathrm{p}<0.01 \mathrm{vs}$ all other groups).

The comet tail moment, an index of both the migration of the genetic material and the relative amount of DNA in the tail, is summarized for each case in Figure 1. This analysis revealed similar results to those described above for the amount of DNA in the tail. The young and aged $\mathrm{C} 57$ mice and the young apoE $\mathrm{E}^{-/-}$mice had similar values of $4.8 \pm 1.9,8.0 \pm 1.1,9.6 \pm 0.9$ arbitrary units, respectively. In contrast, the DNA tail moment of aged apoE ${ }^{--}$ mice was significantly higher at $19 \pm 3.4$ arbitrary units $(\mathrm{p}<0.03)$ than that of the age-matched C57 and young $\operatorname{apoE}^{-/-}$mice $(\mathrm{p}<0.05)$.

We also used an alternative, five-category classification system to categorize DNA migration. Figure 2 (top panel) shows a representative micrograph of the comet for each level of genotoxicity; the results ranged from displayingno comet and no damage to displaying a maximal comet and maximal damage. The bottom graph summarizes the \% of whole blood cells for each level of genotoxicity. The elderly wild-type C57 mice showed a higher \% of cells in levels $0(28 \%)$ and $1(46 \%)$, and similar values were observed in young C57 and young apoE ${ }^{-/}$mice. In contrast, elderly apoE $\mathrm{E}^{-/-}$mice showed a significantly lower $\%$ of cells in genotoxicity levels 0 and 1 and higher $\%$ of cells in genotoxicity levels $2(38 \%), 3$ $(21 \%)$ and $4(15 \%)$.

\section{Discussion}

In the present study, we used the comet assay to measure DNA damage in freshly isolated whole blood cells from C57 and apoE ${ }^{-/-}$mice. We have observed that the level of oxidized DNA was higher in the 72-week-old elderlymice than in the 8-week-old young apoE ${ }^{-/-}$mice; however, similar levels of hypercholesterolemia were observed in both of these groups, but not in age-matched wild-type C57 mice.

The alkaline comet assay is an easy, rapid, inexpensive and sensitive method and has the potential for general applicability [11]. The comet assay quantifies single strand breaks and other damage that affects the migration of DNA out of the nucleus under alkaline electrophoretic
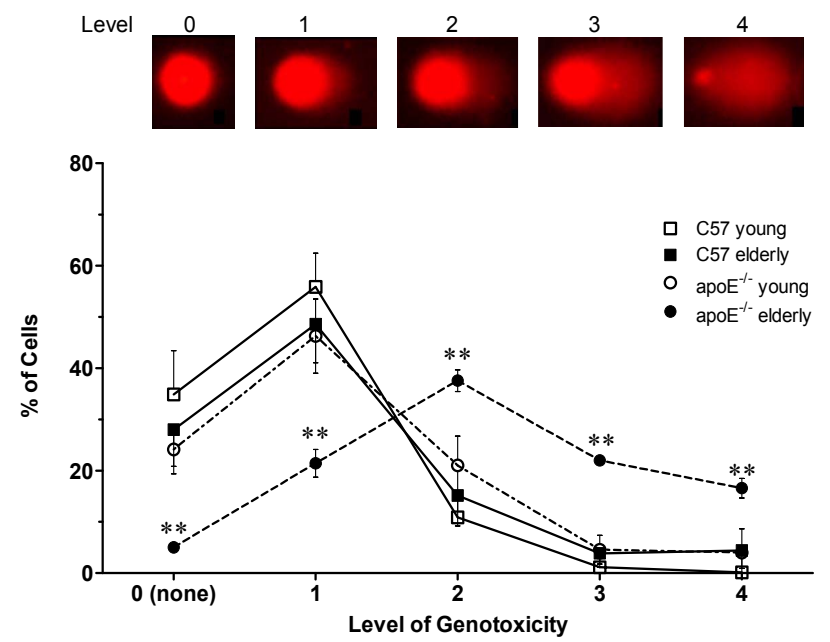

Figure 2. The effects of the concurrence of aging and hypercholesterolemia on DNA damage in $\operatorname{apoE}^{---}$mice. The top panel shows a typical of Comet assay for each level of genotoxicity. The values are shown as the mean \pm SEM. ${ }^{* * *} p$ $<0.01$ vs all other groups at the same time-point (two-way ANOVA). 
conditions [10]. In the present study, a very small amount $(5 \mu \mathrm{L})$ of whole blood was suitable for the comet assay. Using this method, we avoided any additional damage during cell isolation that can occur when it is necessary to prepare cell suspensions using tissues such as aorta, liver and lungs [9]. Other than using the comet assay for the analysis of DNA damage in tissues and lymphocytes $[9,12]$, this technique is also used in the analysis of whole blood in experimental animals and population studies [13].

Hypercholesterolemia results in an excessive production of ROS, which promotes oxidative stress and leads to cell damage and dysfunction [2]. Elevated levels of ROS can damage different types of molecules, including nucleic acids [14]. In the comet assay, the tail moment, which is measured in arbitrary units, is calculated with an imaging system that considers both the length of DNA migration and the intensity in the comet tail, and is an index for induced DNA damage [15]. In the present study, we observed an age-related increase in the comet tail moment in the whole blood cells from apoE ${ }^{-/-}$mice. This finding agrees with the observations from others who also showed an age-related increase in DNA damage in the liver of apoE $\mathrm{E}^{--}$mice [9]. Importantly, our data show that hypercholesterolemia does not necessarily cause DNA damage; we did not observe any significant differences in levels of DNA damage between the wild-type $\mathrm{C} 57$ mice and the young $\mathrm{apoE}^{-/-}$mice that exhibited 6-fold higher levels of plasma cholesterol.

The relative tail intensity, the percentage of tail DNA, has been the preferred and most suitable measure for DNA damage in many studies because it can represent a wide range of damage (from 0 to 100), is independent of the threshold settings of the imaging program used, and is related to the DNA break frequency $[7,16]$. Here, we also performed an analysis of the percentage of DNA in the comet tail, and the data showed that the differences among groups were similar as those above for the tail moment but were more significant. The DNA damage was also significantly increased in the elderly but not in the young $\mathrm{apoE}^{-/-}$mice when compared to age-matched wild-type C57 micedespite similar levels of hypercholesterolemia in both age groups of apo: $\mathrm{E}^{-/-}$. In addition, we scored DNA migration using a five-category classification system that assigned values ranging from 0 (no damage) to 4 (almost all of the DNA is present in the tail). The majority of cells with DNA damage in the normocholesterolemic young and old wild-type animals and in the hypercholesterolemic young $\mathrm{apoE}^{-/-}$mice occurred at levels 0 (no damage) and 1 (light damage) of genotoxicity. In contrast, the $\%$ of cells in the elderly hypercholesterolemic animals was significantly increased at high levels of genotoxicity. These data and data from others [9] support the existence of excessive ROS in the apoE ${ }^{--}$ mouse $[2,4]$, show that excessive oxidative stress frequently causes DNA damage [5], and suggest that aging may contribute to deleterious changes in the DNA and to cellular senescence $[3,17]$.

Normal aging may be accompanied by ROS production that exceeds the antioxidant capacity of the cell [18], leading to DNA damage [19]. In a previous study in $\mathrm{apoE}^{-/-}$mice, Folkmann et al. [9], found that oxidized DNA in the liver increased with age in apoE$^{-/-}$mice compared to their wild-type counterparts. Because the liver is the primary organ of lipid metabolism, the increase in oxidation in the apoE $\mathrm{E}^{-/-}$mice could be due to oxidative stress caused by an altered hepatic lipid metabolism. They also noted that the level of oxidized DNA increased in an age dependent manner only in the liver, whereas no DNA damage was found in the plaque-rich aorta segments or in the normal aorta or lung tissues despite the lungs being a primary destination for a number of inhaled oxidants [13]. However, to the best of our knowledge, our investigation is the first to use whole blood cells from apoE ${ }^{-/-}$mice to report the effects of aging on DNA oxidation and to demonstrate that DNA damage is age dependent. As a whole, it appears that the age-related accumulation of oxidized DNA is a tissuespecific phenomenon and that both liver tissue and whole blood cells show an accumulation of oxidized DNA. However, because no significant difference between the DNA damage in young and elderly wild-type C57 mice was observed, we suggest that the appearance of DNA damage in this experimental animal requires aging and an ROS-related disease to be present simultaneously. This finding corroborates previous results from our laboratory showing vascular senescence in hypercholesterolemic aged apo: ${ }^{-/-}$mice but not in non-atherosclerotic age-matched wild-type C57 mice [3].

In conclusion, the comet assay in whole blood cells is a suitable technique for DNA damage detection in a murine model of spontaneous atherosclerosis, apoE $\mathrm{E}^{-/}$ mice fed a standard chow diet. Observing age-related DNA damage in whole blood cells in apoE $\mathrm{E}^{-/}$mice is important because whole blood cells are easily examined and because the observed results were similar to those obtained using liver tissue, which requires a more laborious and complex technique.

\section{Acknowledgements}

ECV and SSM are supported by the National Council for the Development of Science and Technology (CNPq, Ref. 302582/2011-8 and 302535/2009-8 Grants, respectively) and the State Agency for the Development of Science and Technology (FAPES, Ref. FAPES/CNPq/PRONEX Edital 012/2009). 


\section{REFERENCES}

[1] R. Ross, "Atherosclerosis-An Inflammatory Disease," New England Journal of Medicine, Vol. 340, No. 2, 1999, pp. 115-126. doi:10.1056/NEJM199901143400207

[2] E. C. Vasquez, V. A. Peotta, A. L. Gava, T. M. Pereira and S. S. Meyrelles, "Cardiac and Vascular Phenotypes in the Apolipoprotein E-Deficient Mouse," Journal of Biomedical Sciences, Vol. 19, No. 1, 2012, p. 22. doi:10.1186/1423-0127-19-22

[3] T. M. C. Pereira, B. V. Nogueira, L. C. F. Lima, M. L. Porto, J. A. Arruda, E. C. Vasquez and S. S. Meyrelles, "Cardiac and Vascular Changes in Elderly Atherosclerotic Mice: The Influence of Gender," Lipids in Health and Disease, Vol. 9, No. 1, 2010, p. 87. doi:10.1186/1476-511X-9-87

[4] M. L. Porto, L. C. Lima, T. M. Pereira, B. V. Nogueira, C. L. Tonini, B. P. Campagnaro, S. S. Meyrelles and E. C. Vasquez, "Mononuclear Cell Therapy Attenuates Atherosclerosis in ApoE KO Mice," Lipids in Health and Disease, Vol. 10, No. 1, 2011, p. 155. doi:10.1186/1476-511X-10-155

[5] P. Hasty, J. Campisi, J. Hoeijmakers, H. van Steeg and J. Vijg, "Aging and Genome Maintenance: Lessons from the Mouse?" Science, Vol. 299, No. 5611, 2003, pp. 13551359. doi:10.1126/science. 1079161

[6] S. S. Meyrelles, V. A. Peotta, T. M. Pereira and E. C. Vasquez, "Endothelial Dysfunction in the Apolipoprotein E-Deficient Mouse: Insights into the Influence of Diet, Gender and Aging," Lipids in Health and Disease, Vol. 10, 2011, p. 211. doi:10.1186/1476-511X-10-211

[7] D. P. Lovell and T. Omori, "Statistical Issues in the Use of the Comet Assay," Mutagenesis, Vol. 23, No. 3, 2008, pp. 171-182. doi:10.1093/mutage/gen015

[8] M. Z. Vasquez, "Recommendations for Safety Testing with the in Vivo Comet Assay," Mutation Research/Genetic Toxicology and Environmental Mutagenesis, Vol. 747, No. 1, 2012, pp. 142-156. doi:10.1016/i.mrgentox.2012.05.002

[9] J. K. Folkmann, S. Loft and P. Møller, "Oxidatively Damaged DNA in Aging Dyslipidemic $\mathrm{ApoE}^{-/-}$and Wild-Type Mice," Mutagenesis, Vol. 22, No. 2, 2007, pp. 105-110. doi:10.1093/mutage/gel059

[10] N. P. Singh, M. T. McCoy, R. R. Tice and E. L. Schneider, "A Simple Technique for Quantitation of Low Levels of DNA Damage in Individual Cells," Experimental Cell Research, Vol. 175, No. 1, 1988, pp. 184-191. doi:10.1016/0014-4827(88)90265-0
[11] M. F. Ellahueñe, L. P. Pérez-Alzola, M. Farfán-Urzua, P. González-Hormazabal, M. Garay, M. I. Olmedo and J. A. Last, "Preliminary Evaluation of DNA Damage Related with the Smoking Habit Measured by the Comet Assay in Whole Blood Cells," Cancer Epidemiology Biomarkers \& Prevention, Vol. 13, No. 7, 2004, pp. 1223-1229. http://cebp.aacrjournals.org/content/13/7/1223

[12] C.-H. Chuang and M.-L. Hu, "Use of Whole Blood Directly for Single-Cell Gel Electrophoresis (Comet) Assay in Vivo and White Blood Cells for in Vitro Assay," Mutation Research, Vol. 564, No. 1, 2004, pp. 75-82. doi:10.1016/j.mrgentox.2004.07.013

[13] T. A. Alvarenga, M. L. Andersen, D. A. Ribeiro, P. Araujo, C. Hirotsu, J. L. Costa, M. C. Battist and S. Tufik, "Single Exposure to Cocaine or Ecstasy Induces DNA Damage in Brain and Other Organs of Mice," Addiction Biology, Vol. 15, No. 1, 2010, pp. 96-99. doi:10.1111/j.1369-1600.2009.00179.x

[14] L. J. Marnett, "Oxyradicals and DNA Damage," Carcinogenesis, Vol. 21, No. 3, 2000, pp. 361-370. doi:10.1093/carcin/21.3.361

[15] R. F. Lee and S. Steinert, "Use of the Single Cell Gel Electrophoresis/Comet Assay for Detecting DNA Damage in Aquatic (Marine and Freshwater) Animals," Mutation Research/Reviews in Mutation Research, Vol. 544, No. 1, 2003, pp. 43-64. doi:10.1016/S1383-5742(03)00017-6

[16] A. R. Collins, "The Comet Assay for DNA Damage and Repair: Principles, Applications, and Limitations," Molecular Biotechnology, Vol. 26, No. 3, 2004, pp. 249-261. doi:10.1385/MB:26:3:249

[17] Z. M. Guo, H. Yang, M. L. Hamilton, H. VanRemmen and A. Richardson, "Effects of Age and Food Restriction on Oxidative DNA Damage and Antioxidant Enzyme Activities in the Mouse Aorta," Mechanisms of Ageing and Development, Vol. 122, No. 15, 2001, pp. 1771-1786. doi:10.1016/S0047-6374(01)00298-6

[18] H. F. Zou, E. Stoppani, D. Volonte and F. Galbiati, "Caveolin-1, Cellular Senescence and Age-Related Diseases," Mechanisms of Ageing and Development, Vol. 132, No. 11-12, 2001, pp. 533-542. doi:10.1016/i.mad.2011.11.001

[19] Q. M. Chen, "Replicative Senescence and Oxidant-Induced Premature Senescence. Beyond the Control of Cell Cycle Checkpoints," Annals of the New York Academy of Sciences, Vol. 908, No. 6, 2000, pp. 111-125. doi:10.1111/j.1749-6632.2000.tb06640.x 